\title{
Serial assessment of inflammatory parameters for prediction of septic complications following surgery for colorectal endometriosis
}

\author{
A descriptive, retrospective study
}

\author{
Eliana Montanari (iD) - Lena Maria Reh - Bernhard Dauser · Tudor Birsan · Gernot Hudelist
}

Received: 16 June 2021 / Accepted: 30 June 2021 / Published online: 2 August 2021

(C) The Author(s) 2021

\begin{abstract}
Summary
Purpose To assess whether C-reactive protein (CRP), white blood cell count (WBC) and body temperature changes are suitable parameters for the early detection of septic complications following resection of colorectal deep endometriosis (DE).

Methods Retrospective data analysis of CRP, WBC and body temperature courses following colorectal surgery for DE at a tertiary referral center for endometriosis. Results Out of 183 surgeries performed, 10 major surgical complications were observed, including 4 anastomotic leakages (AL 2\%) and 2 rectovaginal fistulae (RVF 1\%). In the presence of a lower gastrointestinal tract (GIT)-related septic complication or abdominal wall abscess, serum CRP levels were increased starting at postoperative day 2-3. A cut-off value of $10 \mathrm{mg} / \mathrm{dl}$ on day 4 for prediction of early septic complications could be verified (area under the curve 0.94, obtained by receiver operating characteristics analy-
\end{abstract}

\footnotetext{
Supplementary Information The online version of this article (https://doi.org/10.1007/s00508-021-01916-w) contains supplementary material, which is available to authorized users.

E. Montanari, MD, PhD (ه) • L. M. Reh, BSc .

G. Hudelist, MD, MSc

Department of Gynecology, Center for Endometriosis,

Hospital St. John of God Vienna, Vienna, Austria

eliana.montanari@meduniwien.ac.at

E. Montanari, $\mathrm{MD}, \mathrm{PhD}$

Department of Obstetrics and Gynecology, Medical

University of Vienna, Vienna, Austria

B. Dauser, MD, FEBS · T. Birsan, MD, FEBS

Department of General Surgery, Center for Endometriosis, Hospital St. John of God, Vienna, Austria

G. Hudelist, MD, MSc

Stiftung Endometrioseforschung (SEF), Westerstede, Germany
}

sis, sensitivity $88 \%$, specificity $90 \%$, positive predictive value $32 \%$, negative predictive value $99 \%$ ). Additionally, most patients with early septic complications exhibited increased WBC levels starting mainly from day 3-4; however, increased inflammatory parameters could not be observed in one patient with an RVF. Body temperature did not prove useful for early discrimination between uncomplicated cases and those with early septic complications.

Conclusion Relevant elevations of serum CRP and WBC levels were demonstrated in patients with early septic complications following surgery for colorectal DE starting at postoperative day $2-4$. The cut-off value of $10 \mathrm{mg} / \mathrm{dl}$ for CRP levels may serve as an early predictor for lower GIT-related septic complications but should be used with caution in women with suspected RVF development.

Keywords Anastomotic leakage - Body temperature C-reactive protein - Deep endometriosis bowel surgery $\cdot$ White blood cell count

\section{Introduction}

Endometriosis represents a common disease affecting approximately $1.5 \%$ of women of reproductive age [1]. It may involve the ovaries or be detected as mere superficial peritoneal lesions; in severe cases, it may be found at the level of the uterosacral ligaments or rectovaginal septum or affect different organs, such as the urinary bladder, bowel or vagina as deep endometriosis (DE) [2-5]. Symptoms associated with colorectal DE may require surgical excision of endometriotic lesions by rectal shaving, discoid resection or segmental bowel resection. As this surgery may entail a number of complications and risk of disease recurrence, there is still an ongoing debate regarding indications for and the choice of the optimal technique [6-12]. The most 
frequent major complication following colonic resection for DE is anastomotic leakage (AL), which may cause peritonitis and lead to the necessity of reinterventions. Early detection is of pivotal importance since adequate treatment may minimize inflammatory reactions, thus facilitating repair and healing processes [13, 14]; however, associated clinical signs such as fever, signs of peritonitis or prolonged postoperative bowel paralysis are unspecific and may occur late accompanied by rapid clinical deterioration [15]. The C-reactive protein (CRP) levels were found to represent an early indicator of different major surgical complications and postoperative sepsis in abdominal and colorectal cancer surgery [16-20]. CRP and white blood cell count (WBC) levels were also significantly increased in patients with major surgical complications after bowel resection for endometriosis [21]. Furthermore, a decrease of CRP from day 1 to day 3 indicated uncomplicated postoperative courses [21]. A CRP cut-off level of $100 \mathrm{mg} / \mathrm{l}$ on the 4 th day was shown to predict early septic complications, such as bowel fistula, pelvic abscess and infected hematoma [22].

The aim of this study was to compare the postoperative daily changes of CRP, WBC and body temperature after bowel surgery for DE in uncomplicated cases versus cases with septic complications.

\section{Material and methods}

This study was a descriptive, retrospective study analyzing the data of patients who consecutively underwent surgical treatment of colorectal DE between April 2015 and September 2020 at a tertiary referral center for endometriosis. Daily postoperative measurements of CRP, WBC and body temperature were performed routinely until hospital discharge. Exclusion criteria were age under 18 years, a positive history of gynecological malignancy as well as a current diagnosis or suspicion of malignancy and known chronic infectious or inflammatory diseases. Only cases with complete data on CRP and WBC levels at least for the first 3 postoperative days were included in the analyses. The study was approved by the local institutional review board (IRB). All surgical procedures were carried out by the same expert gynecological surgeon in a multidisciplinary team setting. Colorectal endometriosis was confirmed histologically in all cases included in this study. Concerning the surgical technique used for treatment of DE bowel lesions, women either underwent rectal shaving, discoid resection or segmental resection. The following information was retrieved from the patient's charts: woman's age, gravidity, parity, body mass index (BMI), presence of different preoperative pain symptoms such as dysmenorrhea, dyspareunia, dyschezia or dysuria, revised American Society for Reproductive Medicine (rASRM) stage, Enzian classification, CRP levels, WBC levels and body temperature as well as data on the oc- currence of minor and major surgical complications as described by the Clavien-Dindo system [23].

\section{Statistical analysis}

Data were analyzed by descriptive statistics. Patient characteristics are shown as means \pm standard deviations (SD) or as relative values and percentages as appropriate. The courses of CRP, WBC and body temperature in cases without surgical complications are represented as medians together with the $25 \% / 75 \%$ percentiles for each postoperative day, whereas the cases with surgical complications are depicted as individual curves over the hospital stay. Furthermore, sensitivity, specificity and positive and negative predictive values were calculated and a receiver operating characteristic (ROC) curve was built to verify the use of $10 \mathrm{mg} / \mathrm{dl}$ CRP as a cut-off value for detection of early septic surgical complications. IBM SPSS version 21.0 (IBM Corp., Armonk, NY, USA) and Excel from Microsoft Office version 2019 were used for data analysis.

\section{Results}

Between April 2015 and September 2020, 183 women who did not fall under the exclusion criteria underwent surgical treatment for DE of the bowel at our institution. Of these women 10 had a major postoperative surgical complication (10/183, 5.5\%). In total, four anastomotic leakages $(4 / 183,2.2 \%)$, two rectovaginal fistulae (RVF, $2 / 183,1.1 \%)$, one abscess of the abdominal wall $(1 / 183,0.5 \%)$, one abscess of the vaginal cuff $(1 / 183,0.5 \%)$, one postoperative bleeding at the level of the abdominal wall $(1 / 183,0.5 \%)$ and one case of postoperative fever of unknown origin (1/183, $0.5 \%$ ) were observed. Of those cases without any surgical complication, 15 cases were excluded from the analyse because of missing data on CRP and/or WBC values. Therefore, a total of 168 cases were included into the final analyses. Basic characteristics of these women are shown in Table 1. Table 2 gives an overview of the surgical procedures used for resection of colorectal DE and the respective frequencies of different complications.

Fig. 1a depicts the courses of CRP levels for all cases without any postoperative surgical complication as medians together with the $25 \% / 75 \%$ percentiles for each day as well as for those cases with either an AL or an RVF, which are depicted as individual curves for each woman separately. Data are shown in an analogous way for WBC levels (Fig. 1b) and for body temperature (Fig. 1c). In the presence of a lower gastrointestinal tract (GIT)-related septic complication, serum CRP levels were increased over the range of the cases without surgical complications starting at postoperative days 2 to 3 (Fig. la). The WBC levels were increased over the normal range starting from the 3rd to 4 th postoperative day and in 1 of the 4 cases with 
Table 1 Characteristics of patients undergoing surgery for deep endometriosis (DE) of the bowel $(n=168)$

\begin{tabular}{|c|c|}
\hline Patient characteristic & Value \\
\hline Age (years), mean $\pm S D$ & $33.8 \pm 5.6$ \\
\hline Body mass index $\left(\mathrm{kg} / \mathrm{m}^{2}\right)$, mean $\pm \mathrm{SD}$ & $23.7 \pm 3.9$ \\
\hline \multicolumn{2}{|l|}{ Gravidity, $n(\%)$} \\
\hline 0 & $129 / 168(76.8)$ \\
\hline 1 & $32 / 168(19.1)$ \\
\hline 2 or 3 & $7 / 168(4.2)$ \\
\hline \multicolumn{2}{|l|}{ Parity, $n(\%)$} \\
\hline Nulliparity & $139 / 168(82.7)$ \\
\hline Primiparity & 23/168 (13.7) \\
\hline Parity of 2 or 3 & $7 / 168(4.2)$ \\
\hline \multicolumn{2}{|l|}{ Preoperative pain symptom, $n(\%)$} \\
\hline Dysmenorrhea & $168 / 168(100)$ \\
\hline Dyspareunia & $110 / 168(65.5)$ \\
\hline Dyschezia & 40/168 (23.8) \\
\hline Dysuria & 9/168 (5.4) \\
\hline \multicolumn{2}{|l|}{ Affected Enzian compartments, $n(\%)$} \\
\hline Enzian A (vagina, RVS) & $134 / 168(79.8)$ \\
\hline Enzian B (USL, parametria) & $145 / 168(86.3)$ \\
\hline Enzian C (rectum, sigmoid) & $168 / 168(100)$ \\
\hline $\mathrm{C} 1(<1 \mathrm{~cm})$ & $11 / 168(6.6)$ \\
\hline $\mathrm{C} 2(1-3 \mathrm{~cm})$ & 40/168 (23.8) \\
\hline $\mathrm{C} 3(>3 \mathrm{~cm})$ & $117 / 168(69.6)$ \\
\hline Enzian FA (adenomyosis) & $86 / 168(51.2)$ \\
\hline Enzian FB (urinary bladder) & $15 / 168(8.9)$ \\
\hline Enzian FU (ureters) & $13 / 168(7.7)$ \\
\hline \multicolumn{2}{|l|}{ rASRM score, $n(\%)$} \\
\hline Stage 1 & 8/168 (4.8) \\
\hline Stage 2 & $35 / 168(20.8)$ \\
\hline Stage 3 & 26/168 (15.5) \\
\hline Stage 4 & 97/168 (57.7) \\
\hline
\end{tabular}

Table 2 Surgical procedures used for the resection of deep endometriosis (DE) of the bowel $(n=168)$ and the respective frequencies of different complications

\begin{tabular}{|c|c|c|c|c|c|}
\hline & $\begin{array}{l}\text { No compli- } \\
\text { cation } \\
(n=158)\end{array}$ & $\begin{array}{l}\mathrm{AL} \\
(n=4)\end{array}$ & $\begin{array}{l}\text { RVF } \\
(n=2)\end{array}$ & $\begin{array}{l}\text { Abdominal } \\
\text { wall abscess } \\
(n=1)\end{array}$ & $\begin{array}{l}\text { Other com- } \\
\text { plication } \\
(n=3)\end{array}$ \\
\hline \multicolumn{6}{|c|}{ Surgical procedure } \\
\hline Shaving & 8 & 0 & 0 & 0 & 1 \\
\hline $\begin{array}{l}\text { Disc } \\
\text { resection }\end{array}$ & 23 & 1 & 0 & 0 & 1 \\
\hline $\begin{array}{l}\text { Segmental } \\
\text { resection }\end{array}$ & $128^{a}$ & 3 & 2 & 1 & 1 \\
\hline $\begin{array}{l}\text { Protectii } \\
\text { stoma }\end{array}$ & 17 & 0 & 2 & 1 & 0 \\
\hline
\end{tabular}

AL, they started to increase at postoperative day 5 with a peak at day 6 (Fig. 1b). One woman with RVF (yellow curve) did not show any elevation of CRP levels, WBC levels or body temperature (Fig. 1a-c). All of the cases with a surgical complication in Fig. la except for one case with RVF (yellow curve) showed serum CRP levels above the previously described [22] cut-off value of $10 \mathrm{mg} / \mathrm{dl}$ on the $4 \mathrm{th}$ postoperative day.

In Fig. 2a, the individual curves of the courses of CRP levels for each woman with postoperative surgical complications other than AL or RVF are shown. All cases without any postoperative surgical complication are again shown as medians together with the $25 \% / 75 \%$ percentiles for each day. Data are shown in an analogous way for WBC levels (Fig. 2b) and for body temperature (Fig. 2c). The violet curve representing the data of the woman affected by a postoperative abscess of the abdominal wall is similar to those of the patients with a lower GIT-related septic complication, showing increased CRP levels starting at postoperative day 2, which are clearly higher than the cut-off level of $10 \mathrm{mg} / \mathrm{dl}$. The patient with fever of unknown origin (purple curve) also showed CRP levels above $10 \mathrm{mg} / \mathrm{dl}$ on the 4 th postoperative day, although CRP levels did not reach those observed in the other cases of septic complications. on the 4 th postoperative day (Supplemental Fig. 1). The area under the curve was 0.94. Using a cut-off value of $10 \mathrm{mg} / \mathrm{dl}$ for CRP levels for the early detection of septic complications, a sensitivity of $87.5 \%$, a specificity of $89.9 \%$, a PPV of $31.8 \%$ and a NPV of $99.3 \%$ were found in the present study. Excluding the only case with an RVF that showed a CRP value of only $6.02 \mathrm{mg} / \mathrm{dl}$ on postoperative day 4 , a sensitivity of $100 \%$ would have been obtained for the present data, as all of the other cases of septic complications had CRP levels above $10 \mathrm{mg} / \mathrm{dl}$ on the 4 th postoperative day (ranging from 11.6 to $42.2 \mathrm{mg} / \mathrm{dl}$ ).

\section{Discussion}

The present work demonstrates that serum CRP levels significantly increase in patients with major septic surgical complications following colorectal surgery for DE, starting at postoperative days 2 to 3 . In contrast to previous studies [21], we observed this increase to appear later, i.e., on day 2 and 3 instead of day 2 . The same was observed for serum WBC levels, which were increased over the normal range starting from the 3rd to 4 th postoperative day instead of the 2 nd or 3 rd day [21]. In 1 of the 4 cases with AL, WBC levels started to increase even only at postoperative day 5 with a peak at day 6 . Interestingly, one woman with an RVF did not show any elevation of CRP levels, WBC levels or body temperature, which is in contrast to the data published so far. The previously described cutoff level for serum CRP of $10 \mathrm{mg} / \mathrm{dl}$ on the 4 th postoperative day for the detection of early septic compli-
Furthermore, a ROC curve was built for CRP levels 
Fig. 1 Courses of C-reactive protein (CRP) levels (a), white blood cell (WBC) levels (b) and body temperature (c) over the hospital stay from preoperative values (pre-OP) to those measured on each postoperative day. The respective levels for the cases without postoperative surgical complications are shown as medians together with the $25 \% / 75 \%$ percentiles, whereas the values for those with either an anastomotic leakage (blue, orange, dark green and light green curves) or a rectovaginal fistula (red and yellow curves) are depicted individually for each affected woman. Each color represents the same patient over a-c
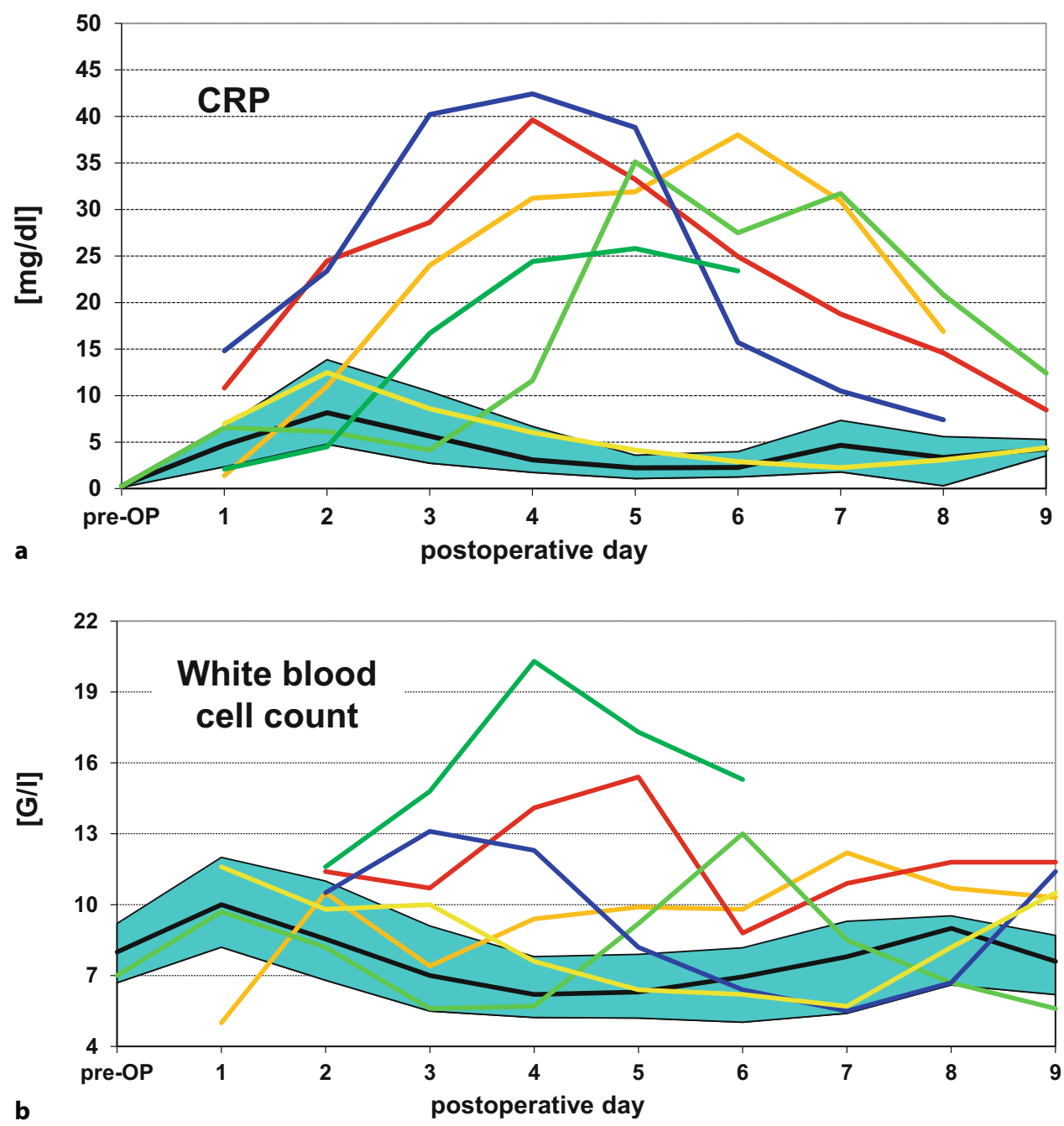
Fig. 2 Courses of C-reactive protein (CRP) levels (a), white blood cell (WBC) levels (b) and body temperature (c) over the hospital stay from preoperative values (pre-OP) to those measured on each postoperative day. The respective levels for the cases without postoperative surgical complications are shown as medians together with the $25 \% / 75 \%$ percentiles, whereas the values for those with any postoperative surgical complication other than anastomotic leakage or rectovaginal fistula are depicted individually for each affected woman. Each color represents the same patient over a-c (violet curve: abscess of the abdominal wall; purple curve: postoperative fever of unknown origin; brown curve: postoperative bleeding at the level of the abdominal wall; grey curve: vaginal vault infection)
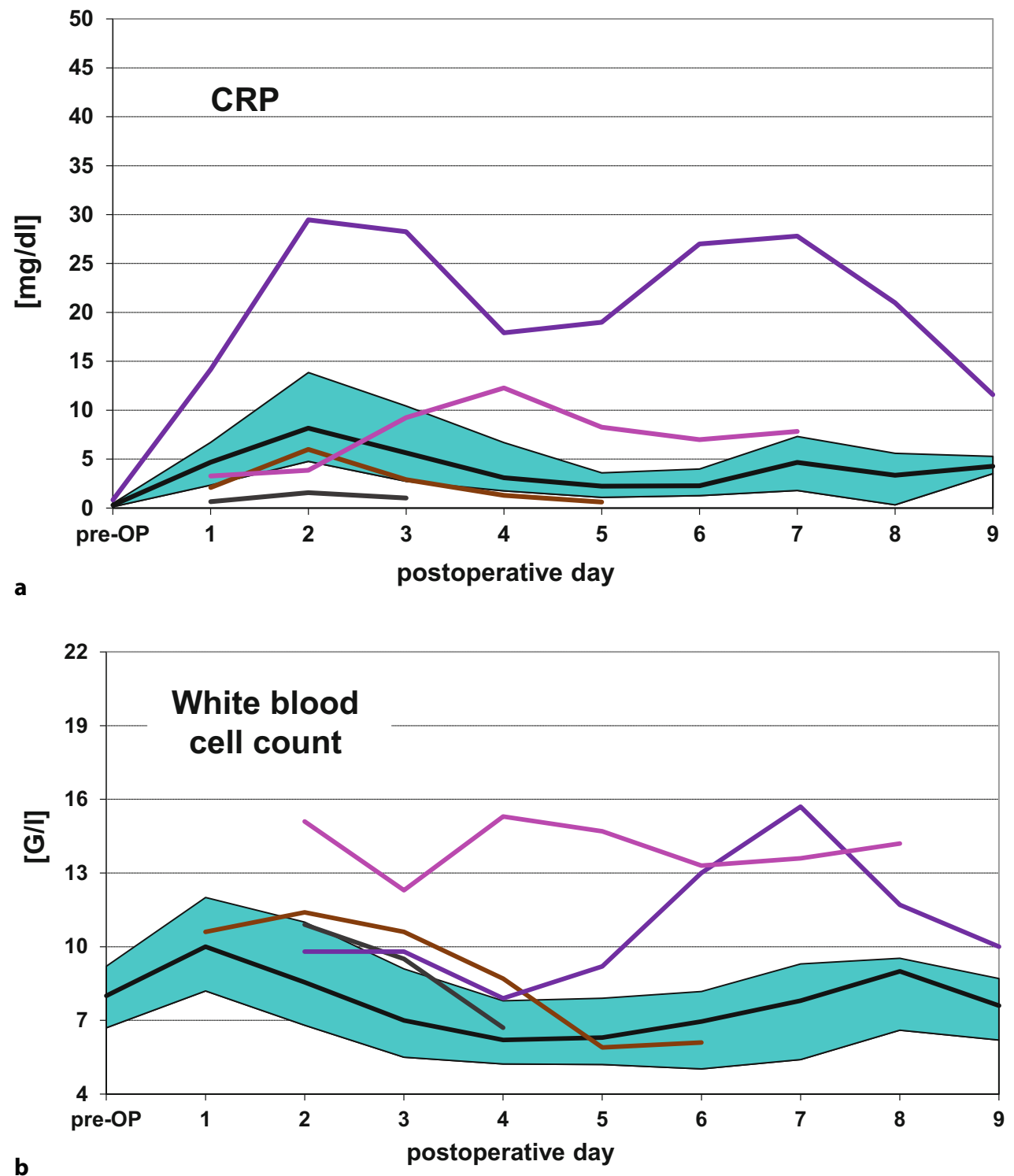

b

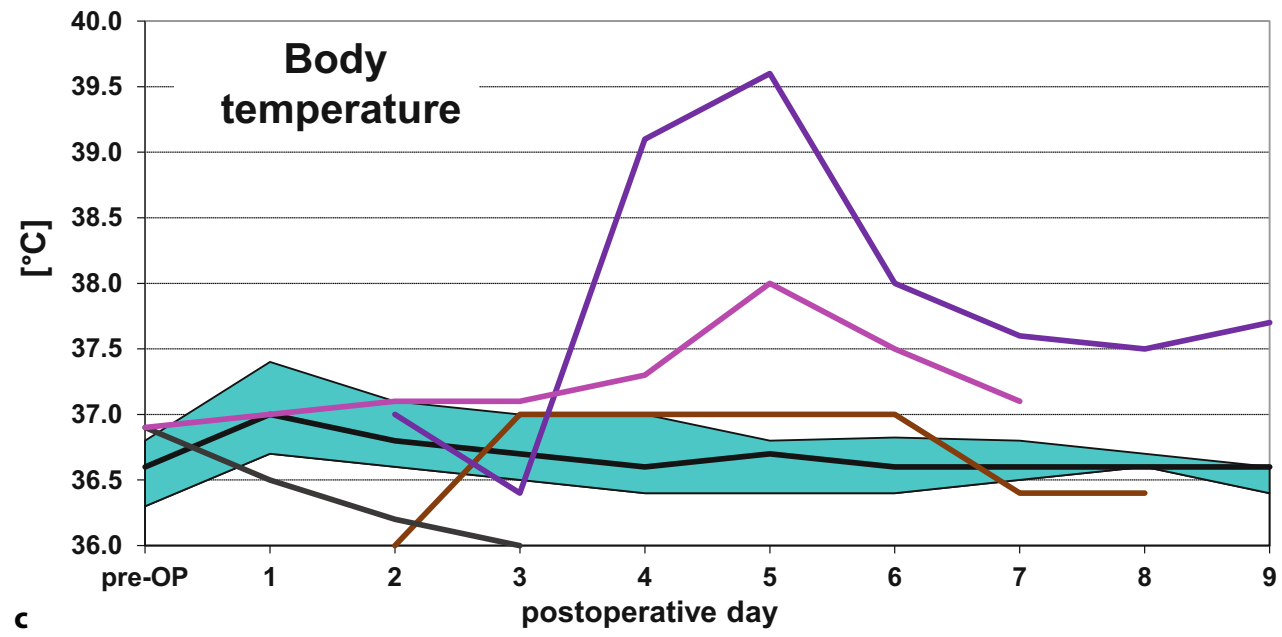


cations [22] also fits the present data, with all of the cases with AL, 1 of the 2 cases with RVF, as well as the case of abdominal wall abscess showing CRP levels between $11.6 \mathrm{mg} / \mathrm{dl}$ and $42.4 \mathrm{mg} / \mathrm{dl}$ on postoperative day 4. Only the mentioned case with RVF would erroneously have been classified as an uncomplicated case using this cut-off value, as it showed a CRP value of $6.02 \mathrm{mg} / \mathrm{dl}$ on postoperative day 4 . As a possible explanation, it could be hypothesized that the protective ileostomy also applied during the surgical procedure may have prevented clinical signs of septic response; however, the second case of RVF did exhibit significant deviations of CRP and WBC levels despite a concomitant diversion stoma which was also applied due to low anastomotic suture lines.

According to previous findings, a decrease of CRP levels from postoperative days 1 to 3 could be considered as an indicator of an uncomplicated postoperative course and therefore be used as a parameter for the decision whether early discharge from hospital after bowel resection for DE is possible [21]. In the present study, one woman with AL and another one with RVF showed a decrease in CRP levels from days 1 to 3 after surgery and would have been discharged too early if this parameter had been used for decision making, whereas all the others showed an increase in CRP levels from days 1 to 3 . Interestingly, as many as $57 \%$ of all uncomplicated cases in this study showed an increase in CRP levels from days 1 to 3 .

In line with the literature, body temperature did not appear to be useful for early discrimination between uncomplicated cases and those with early septic complications.

The main limitations of this study are its retrospective design and the small sample size for the complication group. Regarding its retrospective design, 15 cases had to be excluded due to missing data on serum CRP and WBC levels; however, all data for the cases with major postoperative complications were retrievable, thereby allowing a comparison with the high number of uncomplicated cases. Prospective studies have to further verify the present findings.

\section{Conclusion}

The present work confirms the presence of relevant elevations of serum CRP and WBC levels in cases with lower GIT-related septic complications or abdominal wall abscess starting between postoperative days 2 and 4. The present data support the cut-off value of $10 \mathrm{mg} / \mathrm{dl}$ for serum CRP levels on the 4 th postoperative day for the exclusion of early septic complications; however, women developing RVF may lack significant elevations of WBC and CRP. In addition, the initial decrease of inflammatory parameter levels must be interpreted with caution.

Funding No funding was received for this study.
Author Contribution Eliana Montanari: project development, data collection, data analysis, manuscript writing, Lena Maria Reh: data collection, manuscript editing, Bernhard Dauser: data collection, manuscript editing, Tudor Birsan: data collection, manuscript editing, Gernot Hudelist: project development, manuscript editing.

Funding Open access funding provided by Medical University of Vienna.

\section{Declarations}

Conflict of interest E. Montanari, L.M. Reh, B. Dauser, T. Birsan and G. Hudelist declare that they have no competing interests.

Ethical standards The study was performed in accordance with the ethical standards of the responsible committee on human experimentation (institutional and national) and with the Helsinki Declaration. Due to the retrospective character of the study and the anonymized data analysis, informed consent was not required.

Open Access This article is licensed under a Creative Commons Attribution 4.0 International License, which permits use, sharing, adaptation, distribution and reproduction in any medium or format, as long as you give appropriate credit to the original author(s) and the source, provide a link to the Creative Commons licence, and indicate if changes were made. The images or other third party material in this article are included in the article's Creative Commons licence, unless indicated otherwise in a credit line to the material. If material is not included in the article's Creative Commons licence and your intended use is not permitted by statutory regulation or exceeds the permitted use, you will need to obtain permission directly from the copyright holder. To view a copy of this licence, visit http://creativecommons.org/licenses/by/4.0/.

\section{References}

1. Ballard KD, Seaman HE, de Vries CS, Wright JT. Can symptomatology help in the diagnosis of endometriosis? Findings from a national case-control study-Part 1. BJOG. 2008;115:1382-91.

2. Koninckx PR, Meuleman C, Demeyere S, Lesaffre E, CornillieFJ.Suggestive evidence that pelvic endometriosisisaprogressive disease, whereas deeply infiltrating endometriosis is associated with pelvic pain. Fertil Steril. 1991;55:759-65.

3. Fedele L, Bianchi S, Raffaelli R, Portuese A. Pre-operative assessment of bladder endometriosis. Hum Reprod. 1997;12:2519-22.

4. Chapron C, Dubuisson JB. Management of deep endometriosis. Ann NYAcad Sci. 2001;943:276-80.

5. Keckstein J, Wiesinger H. Deep endometriosis, including intestinal involvement-The interdisciplinary approach. Minim Invasive Ther Allied Technol. 2005;14:160-6.

6. Woods RJ, Heriot AG, Chen FC. Anterior rectal wall excision for endometriosis using the circular stapler. ANZ J Surg. 2003;73(8):647-8.

7. Roman H, Moatassim-Drissa S, Marty N, et al. Rectal shaving for deep endometriosis infiltrating the rectum: a 5-year continuous retrospective series. Fertil Steril. 2016;106(6):1438-1445.e2.

8. Donnez J, Nisolle M, Gillerot S, Smets M, Bassil S, CasanasRouxF. Rectovaginal septum adenomyotic nodules: a series of 500 cases. Br J Obstet Gynaecol. 1997;104(9):1014-8. 
9. Roman H, Abo C, Huet E, et al. Full-thickness disc excision in deep endometriotic nodules of the rectum: a prospective cohort. Dis Colon Rectum. 2015;58(10):957-66.

10. Afors K, CentiniG, Fernandes R, etal. Segmental and discoid resection are preferential to bowel shaving for mediumtermsymptomaticreliefin patients with bowelendometriosis. J Minim Invasive Gynecol. 2016;23(7):1123-9.

11. Donnez O, Roman H. Choosing the right surgical technique for deep endometriosis: shaving, disc excision, or bowel resection? Fertil Steril. 2017;108(6):931-42.

12. Hudelist G, Aas-Eng MK, Birsan T, et al. Pain and fertility outcomes of nerve-sparing, full-thickness disk or segmental bowel resection for deep infiltrating endometriosis-A prospective cohort study. Acta Obstet Gynecol Scand. 2018;97(12):1438-46.

13. Daams F, Wu Z, Lahaye MJ, Jeekel J, Lange JF. Prediction and diagnosis of colorectal anastomotic leakage: a systematic review of literature. World J Gastrointest Surg. 2014;6(2):14-26.

14. Nicksa GA, Dring RV, Johnson KH, Sardella WV, Vignati PV, Cohen JL. Anastomotic leaks: what is the best diagnostic imaging study? Dis Colon Rectum. 2007;50(2):197-203.

15. Hyman N, Manchester TL, Osler T, Burns B, Cataldo PA. Anastomotic leaks after intestinal anastomosis: it's later than you think. Ann Surg. 2007;245(2):254-8.

16. Kragsbjerg P, Holmberg H, Vikerfors T. Serum concentrations of interleukin-6, tumour necrosis factor-alpha, and C-reactive protein in patients undergoing major operations. Eur J Surg. 1995;161(1):17-22.

17. Mustard RA, Bohnen JM, Haseeb S, Kasina R. C-reactive protein levels predict postoperative septic complications. Arch Surg. 1987;122(1):69-73.
18. Matthiessen P, Henriksson M, Hallböök O, Grunditz E, Norén B, Arbman G. Increase of serum C-reactive protein is an early indicator of subsequent symptomatic anastomotic leakage after anterior resection. Colorectal Dis. 2008;10(1):75-80.

19. Meisner M, Tschaikowsky K, Hutzler A, Schick C, Schüttler J. Postoperative plasma concentrations of procalcitonin after different types of surgery. Intensive Care Med. 1998;24(7):680-4.

20. Singh PP, Zeng IS, Srinivasa S, Lemanu DP, Connolly AB, Hill AG. Systematic review and meta-analysis of use of serum C-reactive protein levels to predict anastomotic leak after colorectal surgery. Br J Surg. 2014;101(4):339-46.

21. Riiskjær M, Forman A, Kesmodel US, Andersen LM, Ljungmann K, Seyer-Hansen M. Diagnostic value of serial measurement of C-reactive protein in the detection of a surgical complication after laparoscopic bowel resection for endometriosis. GynecolObstet Invest. 2017;82(4):410-6.

22. Scattarelli A, Carriou M, Boulet L, et al. C-reactive protein assessment to predict early septic complications after laparoscopic bowel resection for endometriosis: a diagnostic study. BJOG. 2019;126(9):1176-82.

23. Dindo D, Demartines N, Clavien PA. Classification of surgical complications: a new proposal with evaluation in a cohort of 6336 patients and results of a survey. Ann Surg. 2004;240(2):205-13.

Publisher's Note Springer Nature remains neutral with regard to jurisdictional claims in published maps and institutional affiliations. 